\title{
Research on the Course Setting and Professionalization of MTI Program
}

\author{
Yuanying Wang \\ School of Foreign Languages, Qingdao University of Science and Technology, Qingdao, China
}

\begin{abstract}
This paper introduced the current development about the education of MTI (professional master) in China and analyzed its development. Due to the deficiency in cultivation for full-time masters in our country, many problems arise, such as the limit of course setting and educational plan for professional master, the unreasonable arrangement of course credits and the poor management for teaching. After comparing with the MATIS program, the writer analyzed the domestic translation market and offered the path of professionalization for MTI graduates.
\end{abstract}

Index Terms-MTI, course setting, translation market, professionalization

\section{THE INTRODUCTION OF MTI PROGRAM IN CHINA}

In order to meet the urgent demand of the market economy in our country which requires the high-quality, professionally specialized practical talents, and according to Interim Regulations on the Approval of the Establishment of Professional Degrees by the Academic Degrees Committee of the State Council and Opinions on the Enhancement and Improvement of Professional Degrees Education by the Ministry of Education of the People's Republic of China, after studying and discussion, in January 2007, the representatives of the $23^{\text {rd }}$ conference held by the Academic Degrees Committee of the State Council voted unanimously to approve the establishment of Master of Translation and Interpreting (MTI). National Committee for MTI Education exclusively designed the curricula syllabus for Master of Translation and Interpreting.MTI is one of the twenty professional degrees (compared to academic degree) in our country, which is complementary to the present translation teaching. It does not follow the teaching mode of academic-oriented or research-oriented programs. Instead, MTI focuses on training high-quality, professionally-specialized translators and/or interpreters.

In the year 2007, 15 universities were rectified to carry out a pilot study of MTI: Beijing Foreign Studies University, Fudan University, Hunan Normal University, Peking University, Nanjing University, Nankai University, Shanghai International Studies University, Tongji University, Southwest University, Xiamen University, Sun Yat-sen University, PLA University of Foreign Languages, Shanghai Jiao Tong University, Central South University, and Guangdong University of Foreign Studies. Among them, Xiamen University has the largest enrollment, reaching to more than 200 people. Among all the applicants of all the universities, the most senior candidate was 60 years old that year, the applicants include staff from administrative units of government, overseas-invested and private enterprises as well as university teachers, etc. From the construction of organizations, hardware facilities to enrollment, everything worked well with satisfactory results, thus other universities followed the lead, applying to the State Council for the approval of establishing MTI. In the year 2009, the Ministry of Education decided to vigorously develop the education of full-time professional degrees for masters. On March 19, 2009, the Ministry of Education of the People's Republic of China issued Opinions of Ministry of Education on the Education of Full-time Professional Master Degree:

"To better meet the urgent demand for high-quality, professionally specialized practical talents in our country seconomy construction and social development, and to actively develop professional degrees education with Chinese characteristics, our ministry determined to expand the enrollment range of full-time professional degrees for university graduating seniors since the year 2009."

By the end of the year 2010, approved by the Ministry of Education of the People's Republic of China, the number of newly established MTI universities reached as many as 236, including Bejing Jiaotong University (Northern Jiaotong University), Beijing Institute of Technology, Beijing University of Posts and Telecommunications, China Foreign Affairs University, Tianjin University, Hebei University, Taiyuan University of Technology, Inner Mongolia University, Liaoning Normal University, Fuzhou University, Nanchang University, Guangxi University for Nationalities, Shandong Normal University, Shandong University of Science and Technology and so forth.MTI is now playing an increasingly important role in training high-quality, professionally specialized practical talents and has become a significant component in Degree and Graduate Education in our country. It is reported by Xinhuanet news on September 12, 2009, that the Ministry of Education of the People's Republic of China has required the universities having the right to receive MTI students in 2010 to rearrange the enrollment members, no less than 5\% in principle, to change their identity from academic degree to professional degree, in addition to the requirement that according to the plan, the extending part mainly allows postgraduate professional degree students. In light of the demand from the Ministry of Education, it is presumably that in 2011, the enrollment of professional degree students will reach 130,000 with an increase surpassing 
16\%. (Xinhuanet, 2010)

\section{ChARACTERISTICS AND REQUIREMENT OF MTI}

With the rapid development of knowledge and technology, there are more and more requirements for further professional classifications. The present world has a higher and specific demand for application and specialization. Under such context, the professional degree emerges in an appropriate situation. The development of professional degree modifies and improves the academic structure, shifts the purpose and model of cultivating talents, to some degree, it strengthens the power and adaptability of the talents. The State Academic Degrees Committee of the State Council of the People's Republic of China announces that it is necessary to establish translation professional degree in China. The reasons are as follows: 1) adapt to the reform and opening-up policy and meet the demand of the socialist construction and modernization; 2) to promote the exchanges between China and the rest of the world; 3) in order to bring up the high-level and practical translation professionals. It puts forward several requirements for the Masters of Translation and Interpreting: 1) Prospective students are supposed to have a sound knowledge of bi-language competence; 2) Prospective students are supposed to have a high-level translation and interpreting skills; 3) Prospective students are supposed to have a wide horizon of world knowledge; 4) Prospective students are supposed to have a good intercultural communicative competence; 5) Prospective students are supposed to have a practical ability of translation and interpretation; 6) Prospective students are supposed to pass China Accreditation Test for Translators and Interpreters (CATTI) when they graduate.

\section{INTRODUCTION OF MATIS PROGRAM STRUCTURE (2011-12)}

In the Center of Translation and Intercultural Studies (CTIS), MA in Translation and Interpreting Studies (MATIS) was established in 1997 in School of Languages, Linguistics and Cultures in Manchester University. The objective is "to equip you with the knowledge and skills for a career in translation" and obtain "other professions which require expertise in cross-cultural communication". MATIS is one of the leading programs in European Masters in Translation (EMT) program, whose purpose is to promote the variety and diversity of European language and culture. Therefore, MATIS program has a very important and instructive role in China's MTI program. By comparing and analyzing the two different yet similar programs, we may get some very interesting and constructive conclusions that may be helpful to our MTI teaching and learning.

MATIS involves the full-time or part-time study. The MA in Translation and Interpreting Studies (MATIS) is available on a full-time and part-time basis.

Full-time MATIS students take the MA program over 12 months. The taught course units are completed over two semesters (end of September-May). The dissertation is written over the summer period and submitted by the beginning of September.

We will mainly focus on the full-time study in this paper. Let us come to the MATIS Program content for 2011-12 to get more detailed comparisons.

MATIS consists of a total of 180 credits, divided as follows:

(1) Specialist optional course units (75 credits), 2) Compulsory core course units (45 credits), 3 )MA dissertation (60 credits)

\section{1) Specialist optional course units}

Specialist course units in translation include:

Translation Technologies (15 credits, all language combinations)

Audiovisual Translation I (15 credits, all language combinations)

Audiovisual Translation II (15 credits, all language combinations)

Literary Translation I (15 credits, all language combinations)

Literary Translation II (15 credits, all language combinations)

Commercial Translation (15 credits, all language combinations)

Scientific and Technical Translation (15 credits, all language combinations)

Translating for International Organizations (15 credits, all language combinations)

Case Studies in Chinese-English, English-Chinese Translation (15 credits)

Specialist course units in interpreting include

Consecutive Interpreting (15 credits, Chinese/Arabic/Spanish/French/German)

Public Service Interpreting (15 credits, Chinese/Arabic/Spanish/French)

Research-oriented course units include:

Translation and Interpreting Studies II (15 credits)

Cross-Cultural Pragmatics (15 credits)

\section{2) Compulsory core course units}

Translation and Interpreting Studies I (15 credits)

Research Methods in Translation \& Interpreting Studies I (15 credits)

Research Methods in Translation \& Interpreting Studies II (15 credits) 


\section{3) Dissertation}

Select from 12-15,000 word dissertation or extended translation/interpreting project.

For details on the content of course units, download the MATIS Handbook. Prospective students should bear in mind that the Handbook and some course unit descriptions will be revised for 2011-12.

\section{Educational System AND Length of Schooling OF MTI}

We are going to list and compare some requirements for MTI students and academic master students from one Chinese university as following.

1) MTI: Full-time study, two years of schooling. The curriculum of MTI is based on the credit system, according to which students should obtain 50 credits, including 22 credits for degree courses, 13 credits for internship, and at least 15 credits for optional courses.

2) Academic master: educational system: 3years. Length of schooling: limited in 4 years.

The curriculum of the program is based on credit system, which requires that the students should obtain 44-48 credits, including 22 credits for degree courses, 13 credits for research work, and at least 9 credits for optional courses.

TABLE I

COMPARISON IN DEGREE COURSES BETWEEN ACADEMIC MASTER OF ENGLISH MAJOR SPECIALIZED IN APPLIED LINGUISTICS AND MTI IN ONE CHINESE UNIVERSITY (PART)

\begin{tabular}{|c|c|c|c|c|c|c|}
\hline & \multicolumn{3}{|c|}{ MTI (Professional master) } & \multicolumn{3}{|l|}{ Academic master } \\
\hline Course Name & Course Type & Class hour & Credit & Course Type & Class hour & Credit \\
\hline $\begin{array}{l}\text { Socialist Theory with Chinese } \\
\text { Characteristics and Practical Research }\end{array}$ & common course & 36 & 2 & Common course & 64 & 2 \\
\hline Chinese Language and Culture & common course & 32 & 2 & common course & 32 & 2 \\
\hline Introduction to Translation & $\begin{array}{l}\text { Specialized } \\
\text { Courses }\end{array}$ & 32 & 2 & $\begin{array}{l}\text { Specialized } \\
\text { Courses }\end{array}$ & 32 & 2 \\
\hline Translation theory and Practice & $\begin{array}{l}\text { Specialized } \\
\text { Courses }\end{array}$ & 64 & 4 & Specialized course & 32 & 2 \\
\hline Interpreting Theory and practice & $\begin{array}{l}\text { Specialized } \\
\text { Courses }\end{array}$ & 64 & 4 & selective course & 32 & 2 \\
\hline Translation for Science and Technology & $\begin{array}{l}\text { Specialized } \\
\text { Courses }\end{array}$ & 64 & 4 & selective course & 32 & 2 \\
\hline Translation for Applied Writing & $\begin{array}{l}\text { Specialized } \\
\text { Courses }\end{array}$ & 64 & 4 & selective course & 32 & 2 \\
\hline $\begin{array}{l}\text { Marxism and Social Sciences } \\
\text { Methodology }\end{array}$ & $\begin{array}{l}\text { Selective } \\
\text { Courses }\end{array}$ & 18 & 1 & selective course & 16 & 1 \\
\hline Computer-aided translation & $\begin{array}{l}\text { Selective } \\
\text { Courses }\end{array}$ & 32 & 2 & selective course & 32 & 2 \\
\hline Cross-cultural Communication & $\begin{array}{l}\text { Selective } \\
\text { Courses }\end{array}$ & 32 & 2 & selective course & 32 & 2 \\
\hline Contrastive studies of English and Chinese & $\begin{array}{l}\text { Selective } \\
\text { Courses }\end{array}$ & 32 & 2 & Specialized course & 32 & 2 \\
\hline Translation Appreciation and criticism & $\begin{array}{l}\text { Selective } \\
\text { Courses }\end{array}$ & 32 & 2 & selective course & 32 & 2 \\
\hline Tourism Translation & $\begin{array}{l}\text { Selective } \\
\text { Courses }\end{array}$ & 32 & 2 & selective course & 32 & 2 \\
\hline Business translation & $\begin{array}{l}\text { Selective } \\
\text { Courses }\end{array}$ & 32 & 2 & selective course & 32 & 2 \\
\hline Literary Translation & $\begin{array}{l}\text { Selective } \\
\text { Courses }\end{array}$ & 32 & 2 & selective course & 32 & 2 \\
\hline On-sight interpreting & $\begin{array}{l}\text { Selective } \\
\text { Courses }\end{array}$ & 32 & 2 & no & & \\
\hline Consecutive Interpreting & $\begin{array}{l}\text { Selective } \\
\text { Courses }\end{array}$ & 64 & 4 & no & & \\
\hline Business Interpreting & $\begin{array}{l}\text { Selective } \\
\text { Courses }\end{array}$ & 32 & 2 & no & & \\
\hline Translation of Chinese Classics & $\begin{array}{l}\text { Selective } \\
\text { Courses }\end{array}$ & 32 & 2 & selective course & 32 & 2 \\
\hline $\begin{array}{l}\text { Translation of Essays and speeches on } \\
\text { policies and international relations }\end{array}$ & $\begin{array}{l}\text { Selective } \\
\text { Courses }\end{array}$ & 32 & 2 & selective course & 32 & 2 \\
\hline Chinese and foreign translation history & $\begin{array}{l}\text { Selective } \\
\text { Courses }\end{array}$ & 32 & 2 & selective course & 32 & 2 \\
\hline Internship & $\begin{array}{l}\text { Internship and } \\
\text { Research Work }\end{array}$ & & 5 & & & 1 \\
\hline Publications & $\begin{array}{l}\text { Internship and } \\
\text { Research Work }\end{array}$ & & 1 & & & 1 \\
\hline Thesis proposal & $\begin{array}{l}\text { Internship and } \\
\text { Research Work }\end{array}$ & & 1 & & & 1 \\
\hline Thesis & $\begin{array}{l}\text { Internship and } \\
\text { Research Work }\end{array}$ & & 6 & & & 8 \\
\hline
\end{tabular}


From the table above, we can come to the following conclusions:

According to the requirements of ministry of education(the Ministry of Education), the courses setting of MTI (professional master) should be focused on application, targeted at professional requirements and centered around the comprehensive accomplishment as well as the enhancement of applied knowledge and ability. Designing courses are to combine theory with practice and practical research, pay more attention to develop the academic ability and the awareness of exploring practical problems. Students are to attach more importance to the development of practical research as well as innovation ability. Besides, they are to also obtain their working experience, shorten the time of adapting to employment and enhance their professional quality as well as employment or pioneering ability. Based on the information above, the author holds the idea that institutions of higher learning should spare more efforts to provide more opportunities of practice for MTI (professional master) students especially when their schooling time is to be limited in two years. Table II is the requirements of credits in a domestic university.

TABLE II

CREDIT REQUIREMENTS OF MTI AND ACADEMIC MASTER'S DEGREE

\begin{tabular}{|l|l|l|}
\hline Credit Requirements & Academic master & MTI(Professional master) \\
\hline Total credits & $44-48$ & 50 \\
\hline Degree courses & 22 & 22 \\
\hline Selective courses & $\geq 9$ & $\geq 15$ \\
\hline Internship and Research Work & 13 & 13 \\
\hline
\end{tabular}

We can conclude from Table II that it is extremely irrational in the credits arrangement for professional master. In the courses setting, professional master pays more attention to theory and sessions. Even though the schooling time for professional master is one year shorter than that of academic master, they are required to accomplish four more credits. Besides, they need to get three more credits in degree courses. However, they have 7 credits less than that of academic masters in the practical research aspects, which is opposite to the requirements that professional masters should attach more importance to practice and application.

In the case of shortened period of schooling for professional master, universities are also required to enhance professional master's practice ability and career background. To achieve this goal, the writer believes that institutions of higher learning should reduce the classroom instruction for professional master and cut back the ratio of degree courses on the precondition of reduced classroom instruction. At the same time institutions of higher learning should also increase the types of professional courses such as standard of profession for students to select relevant courses according to the career they will choose in the future, which will enhance students' initiative of study and specialized skills.

TABLE III

SEQUENCING THE PROBLEMS IN MTI TEACHING

\begin{tabular}{|l|l|l|l|l|l|}
\hline Problem & $\begin{array}{l}\text { No updated } \\
\text { material }\end{array}$ & $\begin{array}{l}\text { No chances of } \\
\text { practice }\end{array}$ & $\begin{array}{l}\text { No internship in international } \\
\text { conference }\end{array}$ & $\begin{array}{l}\text { No qualified and } \\
\text { experienced teacher }\end{array}$ & $\begin{array}{l}\text { No prospect for future } \\
\text { work }\end{array}$ \\
\hline Sequence & 1 & 2 & 3 & 4 & 5 \\
\hline
\end{tabular}

From Table III, we can see that the updated materials are the biggest concern for students. To be a qualified interpreter or translator need the interpreting materials as many as possible. However, many schools are lack of those materials needed urgently. The second and third problem basically belongs to one practical concern, that is, students are lack of chance to interpret or translate. For the domestic translation market, people cannot find jobs or work as many as possible. For fourth problem, as we know, in many universities, a certain number of professors and teachers come to teach the professional masters' course and academic masters' course at the same time. For some teachers, they are more interested in theories than in the practical interpreting. They mainly focused on being a theorist and linguist instead of an interpreter. Due to the above problems, of course students may get negative prospect toward the future work.

In addition, many institutions of higher learning basically evaluate the performance of full-time professional masters by examination. Classroom performance and grades was largely invisible and can't be evaluated effectively. Practical evaluation mainly refers to internship reports, research work which cannot evaluate students objectively. Other factors, lack of communication between students and instructors in school and limited supervision both will deteriorate the situation. This singular evaluation method cannot evaluate professional masters effectively and precisely, which makes it difficult to guarantee the quality of professional masters.

The curriculum design of translator training in MTI program is based on the development of translation competence, because of the differentiated teaching resources, faculties and qualities of students, etc. The suggested courses may be not suitable for all the teaching units of MTI program. The reference framework of translation competence for MTI students is proposed on the basis of analysis of study of translation competence, successful experience of EMT project, as well as the practical situation of social development and present educational conditions in China. This framework is hoped to be served as the minimal requirements for MTI graduates. What's more, the given suggestions on courses are based on the general condition of teaching units, and they can make use of their own strengths to design their own feature courses.

How could we solve all those questions for MTI students and teachers? The writer is going to talk about the domestic 
translation market and analyze the prospect for MTI students, that is, professionalization.

\section{Translation Market AND PROSPECT FOR MTI StUdEnTS}

\section{1) Domestic booming market}

Along with the rapid advancement of economic globalization and China's further opening up to the outside world, China's comprehensive national power is constantly being enhanced, and the exchange and integration of domestic and international markets are speeding up. Therefore, translation's function and position are increasingly improved by the society, and the translation industry develops at all unprecedented speed, thus becoming one of the popular industries. The data provided by TAC (Translators Association of China) shows that, there are more than 15,000 registered translation agencies throughout the country. It is estimated that there are 60 thousand full-time translators, the number of translation employees is up to about 500 thousand. Nationwide, more than 3000 translation companies are active, most of which are located intensively in big cities like Beijing, Shanghai, Guangzhou. etc. Also this is the main reason why some MTI graduates complained they cannot find translating and interpreting work in smaller cities. However, this is just a conservative estimation, and probably this figure will increase up to 1 million (in the future). According to the statistics of Translators Association of China, only in 2010, the value of China's multi-language information market reached 50 billion RMB, an increase at a speed of 30-40 percent per year. The association also predicts that with the quickening globalization process, the value produced by Chinese translation market will probably exceed 100 billion RMB by 2015 for multi-language information processing is all accelerator of modern economy. Multi-language translation industry is regarded as one of the highest output compared to other relevant industries in terms of stimulating industrial development. It can be seen from the analysis of the international institutions that the translations value which worth 1 RMB can bring 5 RMB to the directly related industries. Among the cultural industries, the translation service has become an essential one which is only second to education. China's cooperation with other members of the WTO in every aspect, together with the successful Beijing Olympic Games and Shanghai World Expo, ushered in a golden period for the development of China's translation industry.

\section{2) Professionalization and localization for MTI}

Professionalization is simply a process that draws a clear line between qualified professionals and amateurs. In addition, the professionalization process tends to establish norms of conduct and qualification of membership. Jennifer Mackintosh, the late AIIC president, gives more specific explanation of what professionalization is, in her paper Professionalization: Conference Interpreting-a new profession, she suggests despite many definitions of professionalization, there has been little disagreement in that professionalization involves a social process whereby people come together to engage in an activity as a means of livelihood, inculcating a shared set of attitudes, values and behavior and involving the creation of an association whereby they Can claim professional identity. She further proposes the principal attributes of a profession as follows:

(1) A professional association

(2) Communications

(3) A code of ethics

(4) Professional standards and codified working practices

(5) A membership and admissions system

(6) A recognized training paradigm

(7) External recognition

(8) Professional services to members

(9) Self regulation

(Mackintosh 2005)

In the path of professionalization, training institutions, based on the set standards, should equip themselves with necessary training resources. Trainees take part in the training at appropriate levels. The training result needs to be examined by all authoritative testing and accreditation organization, which is responsible for granting certificates to examinees who have passed the test of certain levels. With a certificate in hand, it would be easier to reach an agreement about the task the translators can fulfill and the salary to be received. This path gives rise to several important factors in defining professionalization, including the quality, working condition, professional association, the ethics of the profession and accreditation, etc.

What makes a professional translator? With specific characteristics of translation as a cross-cultural, cross-lingual, cross-national activity, professional translators should act as linguists and mediators. Professional translators are applied linguists who have a genuine ability dealing with languages and have a deep understanding of them. Professional translators are people who are dedicated to languages influenced by nations, societies, and cultures. They are devoted to improving their ability to understand the source language and rewrite in their target language.

Practical translation should play a major role in the training program. There are three approaches to improve this:

(1) Classroom discussion: The representatives of different kinds of text types are used for analysis and translation. Subjects of translation include scientific, newspaper, legal, fiction, etc. Through those practical assignments, trainees are expected to develop the ability to identify translation problems in various types and genres of texts and to solve them on the basis of taught theoretical assumptions. Courses include revision of translations, translation analysis and 
commentary, terminology work related to the translated texts, etc.

(2) Translation workshop: Professionalism has become a major trend in translator education. Respecting the differences between education and training, a profession-oriented workshop is a great proving ground. It provides good opportunities for the trainees to practice translating, while at the same time, translation skills/techniques/strategies are discussed and applied. The real practice brings the experience and knowledge of the craft.

(3) Internship: Translation and localization companies are offering the opportunity for internship, in which the new translators are trained in how to perform various localization and translation activities such as translation, editing, proofreading, glossary development, DTP (=desktop publishing) and post-DTP quality control. Working in a real-life environment together with experienced translators who help them improve their skills, the new translators acquire experience related to business issues such as handling tight schedules, teamwork, developing and maintaining glossaries, managing the CAT tools, and incorporating a sense of accountability and commitment towards the company's quality assurance standards.

\section{CONCLUSION}

We hope this paper could improve the professional master's practice ability, innovative thinking, and better the training mechanism for the full-time professional master in our country. Based on above analysis, this paper reveals some problems to be tackled in the current MTI educational system, and puts forward some possible solutions and approaches. Translation industry has been one of most increasing industries in China, to take this chance to make further development, MTI students and teachers have to exert their most to develop their potentials to adapt to the professionalized market to perfect their skills, for example, attach more importance to classroom discussion, translation workshop and internship.

\section{REFERENCES}

[1] School of Languages, Linguistics \& $\quad$ Cultures. MATIS program $\quad$ structure 2011-12 http://www.llc.manchester.ac.uk/ctis/ma/matis/features/.

[2] Retrieved May 3, 2010, from http://202.205.177.9/edoas/website18/66/info1206348626642166.htm.

[3] Retrieved May 3, 2010, from http://202.205.177.9/edoas/website18/68/info36368.htm.

[4] http://www.tac-online.org.cn/tran/2009-09/24/content_3156107.htm.

[5] http://baike.baidu.com/view/3446373.htm.

[6] Vienne, J. (2000), which Competence Should We teach to Future Translators, and How.

[7] In C. Schaffner \& B. Adab. (eds.). In Developing Translation Competence. Amsterdam: John Benjamins.

[8] Wang Xiangling. (2008). Developing Students'Translation Competence: A Constructivist Project-based Approach. Hunan Normal University.

[9] Zhong Weihe. (2007). Suggestions on the MTI professional master's cultivation, China translation. (4): 9-10.

[10] Zhong Weihe. (2008). MTI and its challenge on the Chinese Foreign Language Teaching, Voice of Foreign Language Research, (8): 6-11.

[11] The Ministry of Education. Some advice about making good preparations for the training of fill-time professional master. 2009.3.

[12] Huang Zaixi, Yao Chen. (2012) Thoughts about the pattern of the training of professional master. Journal of Chinese communist party committee of Cheng $\mathrm{Du},(6): 90-93$.

[13] MA in Translation. Monterey Institute of International Studies Retrieved Mar.7,2011, from http://www.miis.edu/academics/programs/translation.

[14] Frank Austermuhl. (2006) Electronic Tools for Translators. Beijing: Foreign Language and Research Press.

[15] Huang Youyi and Huang Changqi. (2010) The Translation Industry in China: Current Development and Potential for International Cooperation [online], http://english.people.com.cn/200411/09/eng2004119163236.htm [Accessed 18 March 2010].

[16] European Commission, Directorate-General for Translation. (2009) European Master's in Translation (EMT) Strategy. [online], http://ec.europa.eu/dgs/tralation/programmes/emt/key documents/emt strategy en.pdf [Accessed 14 March 2010].

Yuanying Wang was born in Qingdao, China in 1975. She received her MA degree in School of Foreign Linguistics from Ocean University of China in 2008.

She is a senior lecturer in the School of Foreign Languages, Qingdao University of Science and Technology, Qingdao, China. Her research interests include second language acquisition, cross cultural communication, and language teaching. 